\title{
Public Awareness and Performance Relating to the Implementation of a Low-Carbon Economy in China: A Case Study from Zhengzhou
}

\author{
Liping Chen, David Taylor
}

School of Natural Sciences, Trinity College, University of Dublin, Dublin, Ireland. Email: maggiehouse@gmail.com

Received February $11^{\text {th }}, 2011$; revised March $8^{\text {th }}$, 2011; accepted March $27^{\text {th }}, 2011$.

\begin{abstract}
This paper aims to examine levels of awareness and performance relating to the promotion of a Low-carbon economy (LCE) among the general public in Zhengzhou, China. The data and information used were derived from 300 questionnaires distributed randomly among households in the west, south and north urban districts of Zhengazhou. The results indicate a combination of high awareness with poor understanding of LCE programmes among respondents, with the poor understanding probably due to a shortage of appropriate information from trusted sources and shortcomings in education. Respondents generally showed positive attitudes toward pro-environmental actions, such as refusing to use plastic bags, waste recycling, water and energy conservation. Apart from regulation and policies, they considered education and economic incentives as effective mechanisms to promote LCE implementation. Overall those consulted responded favourably towards the prospect of LCE, with some reservations. Results of the study, though limited, suggest that the general public in China has the potential to be a facilitator of environmental improvements in the country.
\end{abstract}

Keywords: Low-Carbon Economy, China, The General Public, Sustainable Development, Climate Change, Awareness

\section{Introduction}

Climate change is likely to remain a pressing challenge to human society throughout the 21st century, until concerted actions are taken to prevent further global warming-induced effects and to achieve sustainable development. Although the application of science will no doubt be an important component of these concerted actions, reducing climate change impacts will be largely contingent on the active cooperation of people in the implementation of strategies aimed at mitigation [1]. Thus solving the problem of climate change, despite often being posed as a challenge to politicians, scientists and engineers will also require active engagement of the general public.

Emissions of greenhouse gases, notably $\mathrm{CO}_{2}$, to the atmosphere are widely regarded as an important forcer of climate change [2]. Implementation of a Low-carbon economy (LCE) has emerged as a possible solution at regional, national and international levels to the problem of balancing the demands of combating climate change with those of maintaining economic growth and alleviating poverty. LCE refers to an economy that has a mini- mal output of greenhouse gases into the biosphere, aiming to combine the highly efficient use of existing energy resources with the exploitation of new clean energy supplies (e.g. renewable energy sources, such as wind and waves). LCE can therefore be summarised as 3L, i.e. low energy consumption, low pollution, low emission, and $3 \mathrm{H}$, i.e. high energy utilization, high efficiency and high benefits [3]. China, as a major producer of greenhouse gases, has ensured that LCE is at the core of its response to agreements reached at the $15^{\text {th }}$ Conference of the Parties (COP) United Nations Framework Convention on Climate Change (UNFCC) meeting in Copenhagen in 2009, and is now actively promoting LCE through the mass media and other channels for disseminating public information. The China Council for International Cooperation on Environment and Development [4] defined LCE as a new economic, technological and societal system that can achieve its ultimate goal of reducing GHGs emission, while maintaining economic and social development. According to [5], the overall aim of LCE in China is to replace carbon-based fuels through technology innovation as part of the country's strategy for sus- 
tainable development.

Given continually increasing energy demand and a lack of availability of technologies that can be deployed immediately on a large scale, China's emissions will inevitably continue to climb in the next decade, even under the most ambitious mitigation scenarios [6,7]. The challenges to establishing LCE in China are likely to be different from those faced in economically more advanced countries where the population has greater familiarity with the implementation of environmentally-friendly policies, such as the UK and the US. Finding the balance between enhancing living standards through increased consumption, while at the same time reducing carbon emissions, is the fundamental challenge to the establishment of LCE in China. Barriers to successful implementation include the pressure to construct large infrastructure projects, in part to maintain competitive advantage in China, a continued heavy reliance on coal as a source of energy, inefficient energy production and distribution systems, and a continuous and increasing pressure to raise living standards in many parts of the country $[6,8,9]$. Other factors that are likely to hinder the roll out of LCE include the high cost of new technologies, low financial incentives in industries that remain competitive because of low salaries and a lack of inter and intra-sector collaboration. However, embarking on a LCE pathway is also likely to bring opportunities to China, particularly through enhancing the competitiveness of key sectors in the economy internationally [8]. Moreover, failure to achieve the transition to LCE would certainly jeopardise China's ability to develop in a sustainable way and likely weaken the country's position in the international carbon market $[5,6,8]$.

The political will may currently exist in China to facilitate the development of LCE-related policies. However, political will does not necessary transform into effective implementation. A top-down approach has characterised policy-making and implementation in modern China to date, and is a legacy of central planning. Consequently both market-based solutions and public involvement are neither well-developed nor adequately integrated into development planning [9]. Moreover, an integrated bottom-up policy, combining the engagement of stakeholders with stringent enforcement of policies, is essential if the challenges of LCE implementation are to be met $[9,10]$. Research in economically advanced parts of the world in the last two to three decades has confirmed the important role for public participation in achieving sustainable development goals [e.g.,11-13], particularly at local levels [14]. This is because effective implementation of environmental policies at local level requires an appreciation of the behaviour patterns - and possible barriers to changes in these - of individuals [15]. Moreover, [16] revealed that public awareness is essential if a transformation to LCE is to be successfully brought about, while [17] indicated that behavioural changes among the general public were at least as important in moving towards a LCE as technological innovation and environmental management.

A lack of public support has been cited as a reason for problems in implementing environment-friendly policies in China in the past $[9,10,18]$. Although there has been an increased interest in public awareness towards LCE, research targeting the environmental behaviour of members of the general public in China has tended to focus on marketing or on finding ways to increase consumption [9]. Furthermore, no studies have been carried out evaluating public awareness of LCE, and the reasons that underpin LCE, and the likely consequences of moving towards a LCE.

The current research seeks to address a gap in understanding concerning the attitudes and behaviours of the general public towards LCE in an economically rapidly developing part of China. Focusing on Zhengzhou, the capital city of Henan, the research that underpins this paper was guided by the question: to what extent are levels of knowledge, understanding and willingness to act among the residents of Zhengzhou in China likely to facilitate or constrain successful implementation of policies aimed at achieving LCE? Results of the research are intended to appeal to environmental policy makers and planners at local and regional levels in China, and to academics more generally.

\section{Methodology}

\subsection{Research Area}

Zhengzhou is the capital of Henan province in central China (Figure 1). Construction and manufacturing, including aluminum processing, food products, energy, automobile and machinery industries, are the main economic activities in the city. During the $11^{\text {th }}$ Five-Year Plan (2006-2010) period, a total carbon intensity reduction per GDP of $17.3 \%$ was achieved by 2009 (2.3\% higher than the initial target) [19]. Zhengzhou was chosen for study as an economically rapidly developing city that has a large and quickly increasing urban population but still low (compared with many other cities in China) per capita GDP. Zhengzhou can therefore be regarded as something as a microcosm for much of China, where environmental concerns can be outweighed in the policy-making and implementation process by a pressing need to alleviate poverty.

\subsection{Questionnaire-Based Survey}

A target group of 300 households was randomly selected 


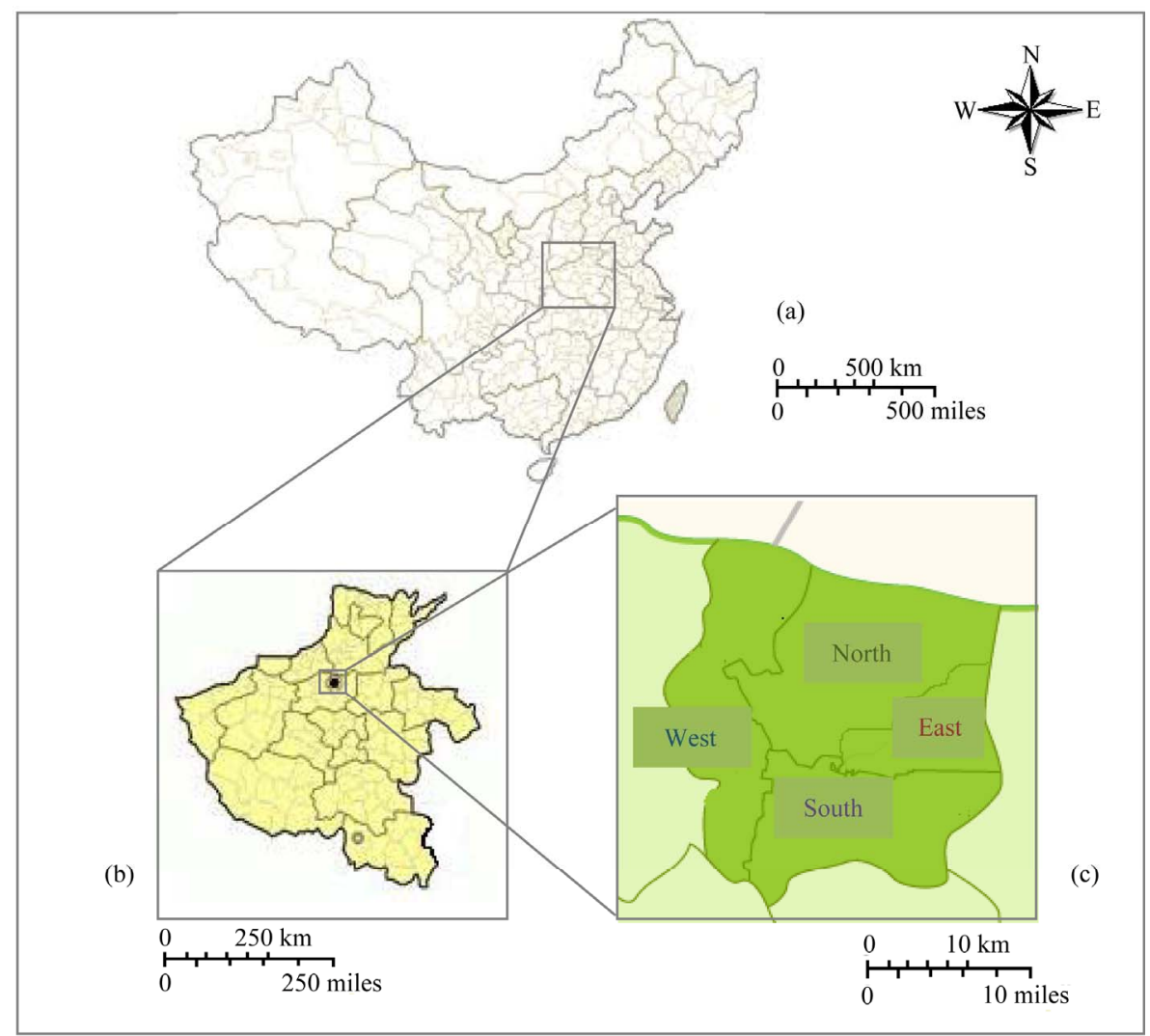

Figure 1. Location map of the study area: (a) China, (b) Henan province, and (c) Zhengzhou urban area.

from the north, west, and south parts of urban Zhengzhou. The east region was excluded from the survey because of the large amount of construction taking place there, and consequently the relatively low number of households. The questionnaire administered comprised ten questions divided into three sections. The First section evaluated respondents' awareness of and attitudes toward LCE and GHGs emission reduction targets. The second section was designed to uncover respondents' understanding and perceptions of LCE. The Third section investigated respondents' practical performance and views of LCE policy instruments. Figure 2 illustrates the research framework.

A pilot of the questionnaire, comprising 20 questions, was administered from $17^{\text {th }}$ June to $20^{\text {th }}$ June, 2010. Based on responses to the pilot questionnaire, socio-demographic questions were removed, as respondents were often unwilling to answer questions relating to their personal economic standing. The full survey was carried out over remainder of the summer of 2010 and involved the random selection of 100 households in each of three parts of Zhengzhou. All questionnaires were distributed by hand to individual householders in their home. The investigators introduced the general background of this survey to respondents and asked permission to conduct follow-up interviews if needed. The survey had a response rate of 57\%: 157 completed questionnaires were collected, out of a total of 300 distributed.

\section{Results and Discussions}

As is evident from the results presented in Table 1, a large majority of respondents were familiar with LCE. Furthermore, attitudes towards implementation of LCE were generally positive, with almost all respondents agreeing to the necessity to implement LCE in China. Most of the respondents claimed that their awareness came from the media (newspapers and magazines, followed by TV), with only a relatively small proportion obtaining information on LCE from public education programmes and discussions with friends and other people. The reliance on mass media as a source of information on environmental issues in China is in line with findings from previous research [18,20,21]. When being asked the importance of implementing LCE, many respondents recognised the need for China, as a major producer of GHG emissions, to take seriously its responsibilities to act to mitigate global climate change. Many respondents acknowledged that LCE would prevent pol- 


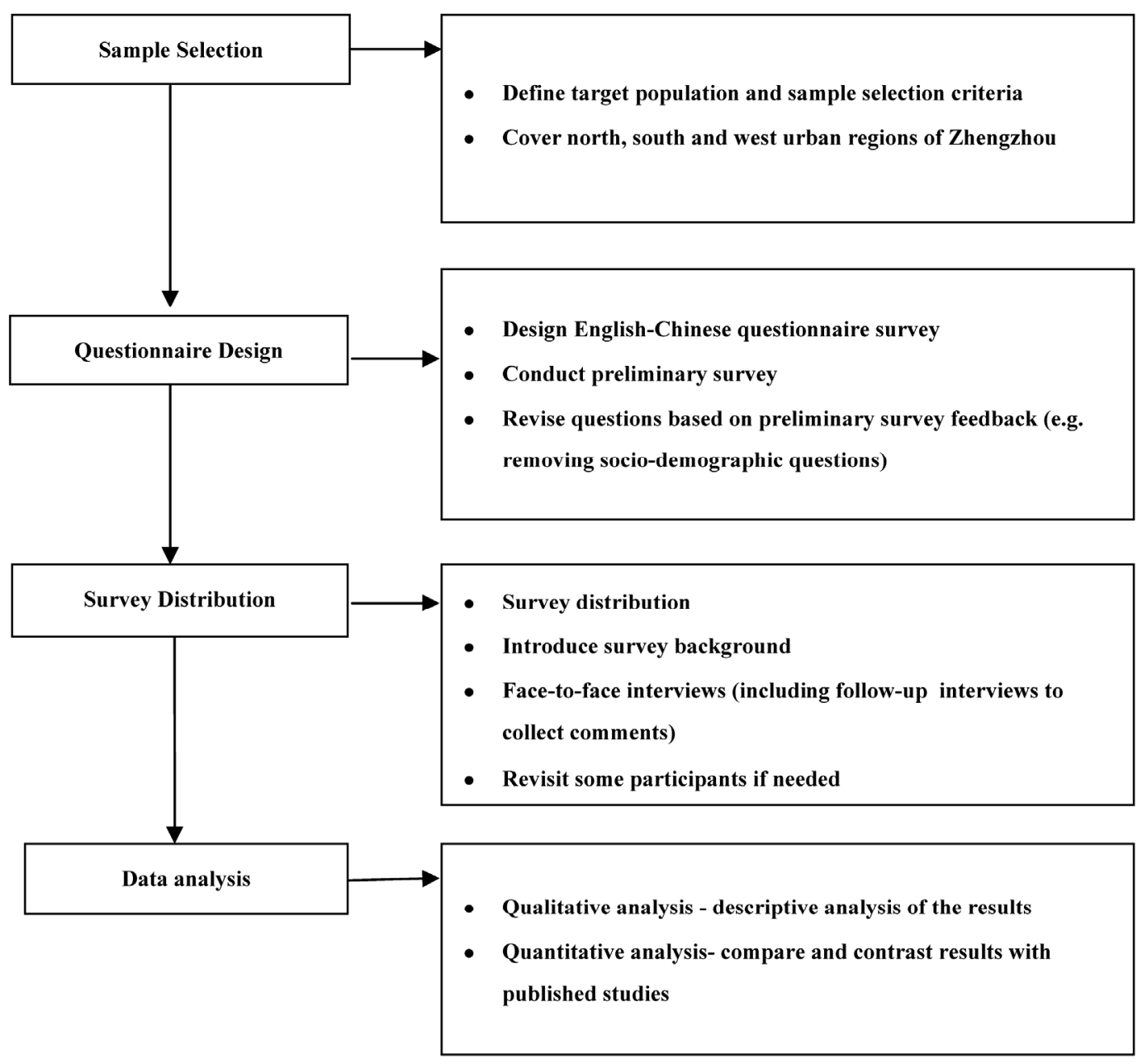

Figure 2. Methodological framework adopted in the research.

lution and protect environment, combat global warming, which was consistent with the domestic sustainable development strategy and would likely reduce the frequency of natural disasters. Furthermore more than half of respondents felt that LCE implementation would lead to improved living conditions and increase the share of natural resources per capita.

With regard to personal actions taken to reduce waste and lower carbon emissions, a large majority of respondents already refused to use plastic bags and disposable products (such as chopsticks, plastic food containers, toothpicks etc.), while more than $60 \%$ frequently engaged in recycling and were willing to or had purchased green products. More than $50 \%$ of respondents conserved water and electricity, while for more than $40 \%$ LCE had become a topic of conversation with friends and relatives.

Despite generally displaying high awareness and engaging in positive actions, concern regarding the development impacts and economic costs was evident. Thus, approximately $30 \%$ of respondents felt that LCE would be detrimental to economic growth, $18 \%$ were concerned about the high price of low carbon products, while a similar proportion expressed worry over the cost of the transformation process (Table 2). Others opined that LCE was unsuitable for present-day China, because they thought implementation of LCE would impact negatively industrial and manufacturing development, while a small number felt that LCE would reduce their standard of living.

Concerns about the consequences of implementing environmental policies are not uncommon, and may stem from mistrust or misinformation, a poor level of understanding of information that is available or a shortage or absence of information from trusted sources. For example, Defra UK [16] interviewed a range of low-carbon related professional bodies and found a low level of understanding of LCE issues. Interviewees, who considered LCE as a means of creating potential business benefits, 
Table 1. Survey results of Question 1 to Question 8.

\begin{tabular}{|c|c|}
\hline Survey Questions & Percentage \\
\hline \multicolumn{2}{|l|}{$\begin{array}{l}\text { Q1. Have you heard of Low-carbon economy } \\
\text { (LCE)? }\end{array}$} \\
\hline Never heard & 8 \\
\hline Familiar & 87 \\
\hline Very familiar & 5 \\
\hline \multicolumn{2}{|l|}{$\begin{array}{l}\text { Q2. Do you think it is necessary to promote LCE } \\
\text { in China? }\end{array}$} \\
\hline Unnecessary & 2 \\
\hline Necessary & 98 \\
\hline \multicolumn{2}{|l|}{ Q3. What would be the future of LCE in China? } \\
\hline Optimistic & 62 \\
\hline Pessimistic & 9 \\
\hline Hard to tell & 28 \\
\hline \multicolumn{2}{|l|}{$\begin{array}{l}\text { Q4. From which information channels that you } \\
\text { heard of LCE? }\end{array}$} \\
\hline News, radio and TV & 42 \\
\hline Public education programmes & 28 \\
\hline Advertisements & 29 \\
\hline Newspaper and magazine & 57 \\
\hline Discussion with friends & 14 \\
\hline \multicolumn{2}{|l|}{$\begin{array}{l}\text { Q5. The world ranking of China as a carbon } \\
\text { emitter? }\end{array}$} \\
\hline No.1 & 41 \\
\hline No.2 & 20 \\
\hline No.3 & 26 \\
\hline No.4 & 5 \\
\hline Not sure & 19 \\
\hline \multicolumn{2}{|l|}{$\begin{array}{l}\text { Q6. Should China be responsible for carbon re- } \\
\text { duction? }\end{array}$} \\
\hline Yes & 95 \\
\hline No & 5 \\
\hline \multicolumn{2}{|l|}{$\begin{array}{l}\text { Q7. What low carbon actions you take in daily } \\
\text { life? }\end{array}$} \\
\hline Refuse to use plastic bags & 90 \\
\hline Refuse to use disposable products & 80 \\
\hline Reduce waste and recycling & 64 \\
\hline Conserve electricity, water, etc. & 50 \\
\hline Purchase low carbon products & 61 \\
\hline Turn off electronic devices & 48 \\
\hline Discuss LCE with friends & 42 \\
\hline Natural disasters prevention & 61 \\
\hline \multicolumn{2}{|l|}{$\begin{array}{l}\text { Q8. Why do you think it is necessary to promote } \\
\text { LCE? }\end{array}$} \\
\hline Global warming & 71 \\
\hline Better living conditions & 54 \\
\hline Economic growth & 32 \\
\hline Sustainable development & 66 \\
\hline Environmental protection & 81 \\
\hline Low energy utilisation rate & 54 \\
\hline Low per capita share of natural resources & 44 \\
\hline Natural disaster prevention & 61 \\
\hline
\end{tabular}

Table 2. Survey results of Question 9 to Question 10.

\begin{tabular}{lc}
\hline \multicolumn{1}{c}{ Survey Question 9 and 10 } & Percentage \\
\hline $\begin{array}{l}\text { Q9. Which mechanisms would play an im- } \\
\text { portant role in promoting LCE? }\end{array}$ & 54 \\
Laws, policies and regulations & 58 \\
Technology innovation & 57 \\
Renewable energy promotion & 20 \\
Economic disincentives (e.g. fines and taxes) & \\
Q10. Why do you think it is unnecessary to & \\
promote LCE? & 17 \\
High capital cost & 5 \\
LCE would affect the current living standards & 18 \\
The price of Low-carbon products is high & 17 \\
LCE is “Poor Economy” & 9 \\
LCE would limit the industrial development & 27 \\
LCE would limit the economic growth & \\
\hline
\end{tabular}

were confused with the interchangeable use of terms such as sustainable, green, eco and environmental. Moreover, research has exposed the weaknesses in the idea that the solution is simply more information (the information-deficit model), in particular its inability to influence directly the behaviour of the target audience (often the general public) [1,22-24]. However, a shortage of appropriate information from trusted sources is often seen as a major factor limiting behavioural change and therefore the effective implementation of environmentfriendly policies. The current study revealed that present levels of understanding of LCE could potentially undermine successful implementation of LCE. As has been found previously, appropriate information from trusted sources can be a necessary component of any transformation towards more pro-environmental actions [24-26].

Pro-environmental actions regarding lifestyles and the products and services the public consume directly and indirectly impact the environment and personal wellbeing [27]. Along the transformation path towards a society characterised by sustainable consumption, finding the balance between limiting unsustainable behaviours and maintaining freedom of choice is a major challenge [6]. Finding this balance requires recognition of the range of behavioural and structural factors, combined with incentives and punitive actions, which are likely to be required $[1,27]$. For example, mechanisms that address an individual's internal motivations for inaction or poor environmental behaviour might be helpful [1,22], such as market-based mechanisms or economic tools. According to this study and others $[26,30,31]$ the general public is willing, for example, to switch to a more fuel-efficient car or to retrofit their home with solar energy when en- 
couragement incentives (e.g. green subsidies, grants, funds and reward schemes) are available. By contrast, a strong dislike of fiscal and monetary disincentives (e.g. taxes, compensation and fines) is commonly expressed.

However, despite the obvious challenges major recent changes in environmental actions in China are evident, and this holds promise for the future. For example, two years after implementation of a ban on domestic plastic bags in 2008, 90\% of respondents in the current study said they refused to use plastic bag. This finding is in line with a study from southern China where $70 \%$ of urban respondents now use their own recyclable shopping bags [28]. Outside of China the situation is similar. In Ireland, for example, a tax on plastic bags cut usage by $90 \%$ within a matter of weeks of its introduction, while at the same time enriching the state's finances, yielding over 12.7 million Euros in 2003 [29].

Similarly impressive changes have been made since the first introduction of the National Waste Recycling Programme in China a decade or so ago. 65\% of respondents in the current study maintained that they recycle their household waste; $52 \%$ of Tianjing residents recognise waste recycling as their daily must-do action [32]; $86 \%$ of Guangzhou residents recycle their household waste on a weekly basis; and $70 \%$ of Ningbo residents participate in the waste sorting programme and expressed a willingness to attend waste sorting classes [25,33]. Changes in consumption are also evident, with the purchasing of green products increasingly popular [25,28, 32]. However, the price of green products is normally higher than standard consumer items (i.e. 15-30\% more expensive, generally), and therefore beyond what many can afford [34].

Respondents in the current study generally displayed a high level of trust in the government, particularly with regard to technology innovation and education provision. During the past three decades, environmental policies in China have evolved and deepened at local, regional and national levels. The focus of policies changed from pollution control to prevention, while management style evolved from reliance on executive power to the use of encouragement-based tools [30]. As a rapidly emerging industrial and agricultural powerhouse with a growing demand for resources and with a population that is still, in many parts of the country, burdened with poverty, the challenges to implementing a LCE in China are perhaps greater than for any other nation. A close working relationship between the Government, industry and the general public is likely to be essential to the successful implementation of LCE. The evidence presented here, albeit from a limited study, suggests that the general public is unlikely to impede roll out of LCE in China. More likely they have the potential to be strong agents for environmental improvements in the country, including implementation of LCE.

\section{Conclusions}

The current research focusing on a sample of residents of Zhengzhou was stimulated by an interest in determining the extent to which the awareness and attitudes of the Chinese public are likely to facilitate or constrain movement of the economy to one less dependent on fossil fuels.

The findings suggest that participants generally display a high awareness towards LCE while their understanding and knowledge of key issues is relative poorly developed, which is possibly derived from the lack of information. However, rather than being unknowledgeable about environmental problems and resistant to sustainable consumption, respondents showed a strong willingness to learn and take actions aimed at facilitating the transition to a LCE. Pro-environmental actions that already occur include refusing to use plastic bags, waste recycling, green products purchasing and water/electricity conservation. In response to the question "which LCE promotion measure are you in favour of ?” The data demonstrate that the public generally are pro technology innovation, educational provisions, and encouragementbased market mechanisms (such as green subsidy and funds), while displaying far less satisfaction with economically punitive measures (such as fines and taxes). Furthermore, respondents expressed strong trust in the government and acknowledged the efforts that government put so far in terms of local environmental protection. Overall respondents were in favour of a transition towards LCE, while retaining some reservations, notably concerning the development costs. The general public in China may therefore become a strong agent for environmental improvements in the country, including the implementation of LCE.

Participants were highly concerned of their personal details and displayed strong reluctance to answer personal detail questions such as "What is your job?" "What is your educational level?" "What is your general income per month?” Age, gender, occupation and education are important correlates with opinions on environmental protection issues [31,35]. Notwithstanding this, socio-demographic information questions were removed from the questionnaire administered in the full survey. This weakened the survey, but was a necessary step. Further investigation of socio-demographic information as a basis for more detailed and nuanced examinations of environmental attitudes and actions in China is, however, highly recommended. 


\section{Acknowledgements}

This study is supported by Trinity College Dublin. The authors would like to thank Dr. Carlos Rocha and Professor Anna Davies for their very supportive actions during the course of the research that underpins this paper. The author would like to thank the supervisor Professor David Taylor and the entire family for their genuine love, continuous support, and endless encouragement. Thanks are also due to the people of Zhengzhou for their willingness to participate in the research, and to the research assistants for their assistance in gathering information, and to the reviewers of an earlier version of this paper for their highly constructive comments.

\section{REFERENCES}

[1] J. Blake, “Overcoming the 'Value-Action Gap' in Environmental Policy: Tensions between National Policy and Local Experience,” Local Environment, Vol. 4, No. 3, 1999, pp. 257-278. doi:10.1080/13549839908725599

[2] B. W. Terwel, F. Harinck, N. Ellemers and D. D. L. Daamen, "Voice in Political Decision-Making: The Effect of Group Voice on Perceived Trustworthiness of Decision Makers and Subsequent Acceptance of Decisions," Journal of Experimental Psychology: Applied, Vol. 16, No.2, 2010, pp. 173-186. doi:10.1037/a0019977

[3] G. L. Wang, “Low-Carbon Economy: ABC,” Petroleum Industrial Publisher, Beijing, 2010.

[4] The China Council for International Cooperation on Environment and Development, "The Study of Measures to Implement Low-Carbon Economy in China,” The State Council of China, Beijing, 2009.

[5] J. Bing, Z. Q. Sun and M. Q. Liu, “China’s Energy Development Strategy under the Low-carbon Economy," Energy, Vol. 35, No. 11, 2010, pp. 4257-4264. doi:10.1016/j.energy.2009.12.040

[6] G. Fang, N. Stern, O. Edenhofer, X. Shanda, K. Eklund, F. Ackerman, L. Li and K. Halding, "Going Clean - The Economics of China's Low-Carbon Development,” Stockholm Environment Institute and the Chinese Economists 50 Forum, Beijing, 8 December 2009.

[7] C. Flachsland, G. Luderer, J. Steckel, B. Knopf and O. Edenhofer, "International Emissions Trading and the Global Deal,” Potsdam Institute for Climate Impact Research, Potsdam, 2009.

[8] China Academy of Science Sustainable Development Strategy Study Group, “China Sustainable Development Strategy Report 2010 - Green Development and Innovation,” Science Press, Beijing, 2010.

[9] Q. Liu and H. M. Li, "A Survey and Analysis on Public Awareness and Performance for Promoting Circular Economy in China: A Case Study from Tianjin,” Journal of Cleaner Production, Vol. 17, No. 2, 2009, pp. 265-270. doi:10.1016/j.jclepro.2008.06.003
[10] K. M. Zhang and Z. G. Wen, "Review and Challenges of Policies of Environmental Protection and Sustainable Development in China,” Journal of Environmental Management, Vol. 88, No. 4, 2008, pp.1249-1261. doi:10.1016/j.jenvman.2007.06.019

[11] P. Tucker and D. Speirs, "Model Forecasts of Recycling Participation Rates and Material Capture Rates," Research Report, University of Paisley Environmental Technology Group, July 2002.

[12] T. Carmen and K. Sybille, "Promoting Sustainable Consumption: Determinants of Green Purchases by Swiss consumers," Psychology and Marketing, Vol. 20, No. 10, 2003, pp. 883-902. doi:10.1002/mar.10101

[13] S. McDonald and C. Oates, "Reasons for Non-Participation in a Curbside Recycling Scheme," Resources, Conservation and Recycling, Vol. 39, No. 4, 2003, pp. 369-385. doi:10.1016/S0921-3449(03)00020-X

[14] P. Macnaghten and M. Jacobs, "Public Identification with Sustainable Development: Investigating Cultural Barriers to Participation," Global Environmental Change, Vol. 7, No. 1, 1997, pp. 5-24. doi:10.1016/S0959-3780(96)00023-4

[15] S. Barr and A. Gilg, "Conceptualizing and Analyzing Household Attitudes and Actions to a Growing Environmental Problem: Development and Application of a Framework to Guide Local Waste Policy,” Applied Geography, Vol. 25, No. 3, 2005, pp. 226-247. doi:10.1016/j.apgeog.2005.03.007

[16] Department of Environment Food and Rural Affairs, "Skills for a Low Carbon and Resource Efficient Economy,” Pro Evidence, Warwickshire, 2007.

[17] J. Skea, and S. Nishioka, "Policies and Practices for a Low-Carbon Society,” Climate Policy, Vol. 8, 2008, pp. 5-16. doi:10.3763/cpol.2008.0487

[18] Y. P. Cai, G. H. Huang, Z. F. Yang, W. Sun and B. Chen, “Investigation of Public's Perception towards Rural Sustainable Development Based on a Two - Level Expert System,” Expert Systems with Applications, Vol. 36, No. 5, 2009, pp. 8910-8924. doi:10.1016/j.eswa.2008.11.032

[19] Statistical Bureau of Henan Province, "Statistical Yearbook of Henan, 2009,” 2009. www.ha.stats.gov.cn/hntj/lib/tjnj/2009/indexch.htm

[20] China Academy of Science Sustainable Development Strategy Study Group, "China Sustainable Development Strategy Report 2009 - China’s Approach towards a Low Carbon Future,” Science Press, Beijing, 2009.

[21] B. Xue, X. P. Chen, Y. Geng, X. J. Guo, C. P. Lu, Z. L. Zhang and C. Y. Lu, "Survey of Officials' Awareness on Circular Economy Development in China: Based on $\mathrm{Mu}-$ nicipal and County Level," Resources, Conservations and Recycling, Vol. 54, No. 12, 2010, pp. 1296-1302. doi:10.1016/j.resconrec.2010.05.010

[22] R. De Yong, "Changing Behaviour and Making it Stick: The Conceptualisation and Management of Conservation Behaviour,” Environment and Behaviour, Vol. 25, No. 3, 1993, pp. 485-525. doi:10.1177/0013916593253003 
[23] A. R. Davies, "Is the Media the Message? Mass Media, Environmental Information and the Public," Journal of Environmental Policy and Planning, Vol. 3, No. 1, 2001, pp. 319-323. doi:10.1002/jepp.92

[24] P. W. Schultz, "Knowledge, Information, and Household Recycling: Examining the Knowledge-Deficit Model of Behavioural Change,” In: T. Dietz and P. C. Stern, Eds., New Tools for Environmental Protection: Education, Information and Voluntary Measures, National Academy Press, Washington, 2002.

[25] P. Huang and X. Zhang, "Survey and Analysis of Public Environmental Awareness and Performance in Ningbo, China: A Case Study on Household Electrical and Electronic Equipment," Journal of Cleaner Production, Vol. 14 , No. 18, 2006, pp. 1635-1643. doi:10.1016/j.jclepro.2006.02.006

[26] A. R. Davies, "Does Sustainability Count? Environmental Policy, Sustainable Development and the Governance of Grassroots Sustainability Enterprise in Ireland,” Sustainable Development, Vol. 17, No. 3, 2009, pp. 174-182. doi:10.1002/sd.374

[27] T. Jackson, "Motivating sustainable consumption: A review of Evidence on Consumer Behaviour and Behavioural Change,” A Report to the Sustainable Development Research Network, University of Surrey, Guildford, 2005.

[28] B. Xue, X. P. Chen, Y. Geng, X. J. Guo, C. P. Lu, Z. L. Zhang and C. Y. Lu, "Survey of Officials' Awareness on Circular Economy Development in China: Based on $\mathrm{Mu}-$ nicipal and County Level,” Resources, Conservations and Recycling, Vol. 54, No. 12, 2010, pp. 1296-1302. doi:10.1016/j.resconrec.2010.05.010

[29] A. Fourie, "Balancing Environmental and Social Considerations in a Developing Country: The Great South African Plastic Bag Debate,” Waste Management, Vol. 24, No. 6, 2004, p. 531.doi:10.1016/j.wasman.2004.05.001

[30] K. M. Zhang and Z. G. Wen, "Review and Challenges of Policies of Environmental Protection and Sustainable Development in China," Journal of Environmental Management, Vol. 88, No. 4, 2008, pp.1249-1261. doi:10.1016/j.jenvman.2007.06.019

[31] J. D. Francis and L. Busch, "What We Now Know about 'I Don't Knows',” Public Opinion Quarterly, Vol. 39, No. 2, 1975, pp. 207-218. doi:10.1086/268217

[32] Q. Liu, and H. M. Li, “A Survey and Analysis on Public Awareness and Performance for Promoting Circular Economy in China: A Case Study from Tianjin,” Journal of Cleaner Production, Vol. 17, No. 2, 2009, pp. 265-270. doi:10.1016/j.jclepro.2008.06.003

[33] T. F. Ma, "Research on Public Environmental Awareness and Present Situation Analysis in Guangzhou: A Case Study in Panyu District,” Urban Studies, Vol. 10, No. 2, 2003, pp. 7-52.

[34] An Eaton White Paper, "State of Green Products in China Report," 2008.

[35] H. D. Minh, N. Alain and S. C. Ana, "A Survey on the Public Perception of CCS in France,” International Journal of Greenhouse Gas Control, Vol. 3, No. 5, 2009, pp. 633-640. doi:10.1016/i.ijggc.2009.05.003 